\title{
Research on Applied Talent Training Related to Mechanical and Electronic Engineering
}

\author{
Zengsheng Wang \\ School of Mechanical Engineering \\ Huanghe Science and Technology College \\ Zhengzhou, China
}

\author{
Hansong Yang \\ School of Mechanical Engineering \\ Huanghe Science and Technology College \\ Zhengzhou, China
}

\author{
Qin Zhang \\ School of Mechanical Engineering \\ Huanghe Science and Technology College \\ Zhengzhou, China
}

\begin{abstract}
Mechanical and electronic engineering is a comprehensively applied subject integrating mechanics, electronics, control, computer and so on, as a specialty, the mechanical and electronic engineering is to train students' capabilities in practice and innovation on the subjects given above. This article analyzes typical training modes of the mechanical and electronic engineering in colleges and universities in the recent years, which is expected to be references for the construction and reform of the specially.
\end{abstract}

Keywords-Mechanical and Electronic Engineering; applied; talent training mode

\section{INTRODUCTION}

The mechanical and electronic engineering (hereinafter referred to as MEE) features wide application, diverse knowledge as well as rapid technical renewal and expansion, and the MEE talents are urgently needed for the economic construction across the country. The MEE is a compound specialty, due to the differences in regional economic development, service orientation, subject background and development history, colleges and universities keep big differences in talent training goal, mode, course system, course content and practical teaching, each of which has features of its own[1]. In recent years, the MEE construction and reform modes in colleges and universities mainly include the following.

\section{TyPiCAL TALENT TRAINING MODES RELATIVE TO THE MEE}

A. A Talent Training Mode on the Basis of Production-StudyResearch Integration

Reference [2] explores the 3E (namely expansion,

The project is funded by Henan-Stationed Undergraduate Education Reform Pilot Specialty-Mechanical Design and Manufacturing and Automation, Henan- Stationed Comprehensive Specialty Reform PilotMechanical Design and Manufacturing and Automation, Henan- Stationed Non-Governmental College Brand Specialty-Material Molding and Control Engineering projects. education and exploration) applied talent training model, building a main line of course system with contents as mechanical design, mechanical manufacturing, mechanical and electrical control and achieving the course teaching innovation. In the meantime, it raises implementing measures for the $3 \mathrm{E}$ applied talent training, including: guide and ensure students to participate in teaching researches, build a college -enterprise cooperation platform for training applied talent, create an extracurricular research and innovation training platform on the basis of technical innovation groups consisting of students, and set up all kinds of incentive systems on the basis of students' research and innovation training funds.

\section{B. A MEE Talent Training Mode with a Work-Study Integration}

Reference [3], based on the training of students' vocational skills, it creates a MEE course system and sets up a work taskorientated course system and teaching contents. Within the framework of "Technical platform + specialty direction", this article is focused on the students' comprehensive capabilities training to create teaching contents for the course system "core courses and comprehensive training + special skills training for posts" so as to train students' technical abilities, thought methods and comprehensive quality to solve comprehensive specialty problems.

"Fig. 1" shows the course system. A practical teaching system is designed with experiment, practice, step-by-step implementation for the ability development. Both professional theory teaching and experiment teaching are completed through the study-operation integration in labs; the comprehensive training is completed in the production practice center of college-enterprise cooperation for campus life; Practices in enterprise are all completed via in-post work. The core courses learning and training of comprehensive project practice make students acquire comprehensive vocational skills in the professional field of their own. The goal of talent training is to achieve through cooperating with enterprises to jointly build in-campus practice base and off-campus practice 
base, which is a full embodiment of a production-study integration college-running mode, achieving the work-study integration in talent training. Refer to "Fig. 2" for the talent training system framework.

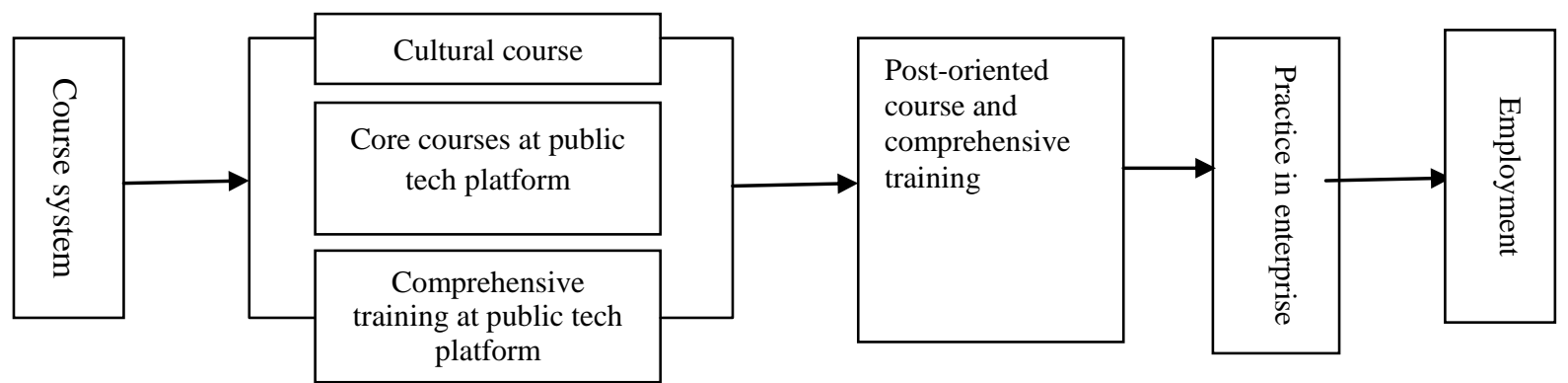

Fig. 1. MEE Talent Training Course System.

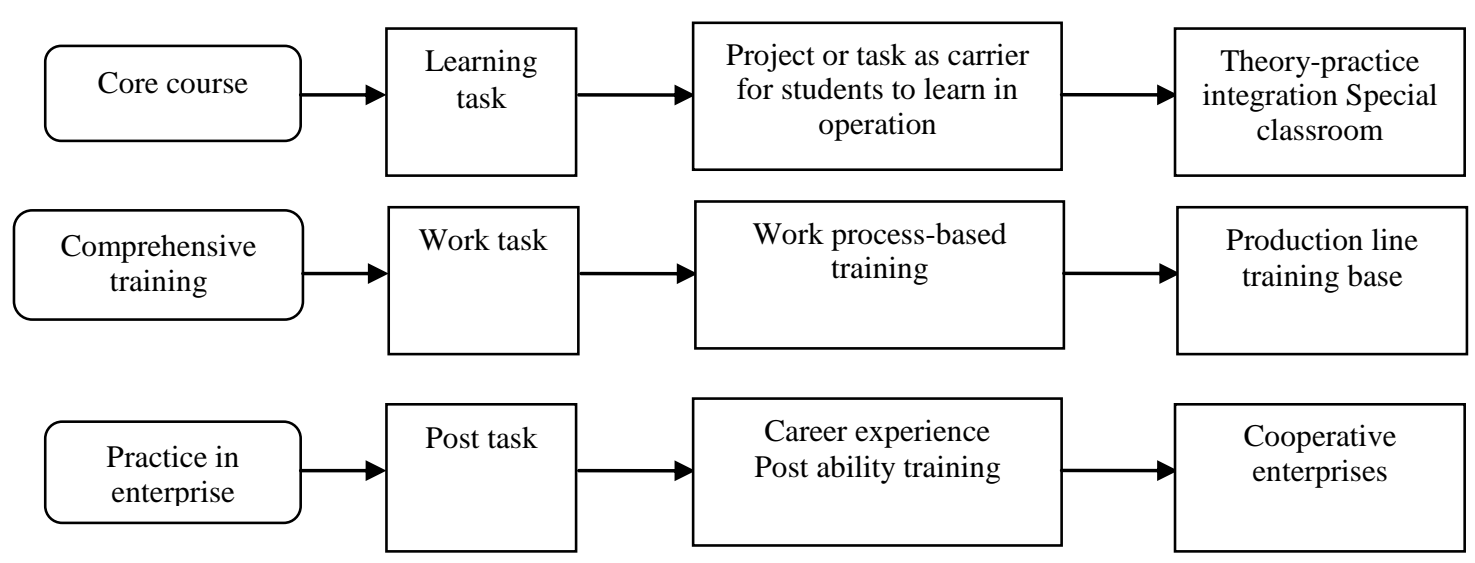

Fig. 2. Talent training system framework with a work-study integration.

\section{MEE Talent Training on the Basis of CDIO Concept}

Reference [4], based on the reform of CDIO engineering education, this article raises an engineering talent training mode where abilities are oriented, projects act as carriers, bother knowledge learning and ability training are stressed. The whole project system, as a carrier, consists of three levels of projects which are closely connected with each other: namely level III project which is focused on the application of basic knowledge of single course (or two- course connection); level II project which aims at the organic integration of teambased knowledge of multiple courses, able to fully embody the whole course of Conceive-Design-Implement-Operate; and level I project which aims at the comprehensive application and innovation of professional knowledge. Besides, the theory-teaching hours are greatly reduced with the experience and practice teaching hours increased so as to form a staged and step-by-step practice teaching mode containing four levels as basic experiment, comprehensive experiment and project-based experiment and engineering practice.

\section{A MEE Training Mode with Innovation and Start-Up Education Integrated}

Reference [5] with the establishment of required courses for innovation and start-up and certification course modules, the innovation and start-up education is integrated to the talent training program. And the innovation and start-up education is deeply integrated to the professional education with the faculty structure optimized, and the innovation education is to promote the professional education. Building a practical platform for the innovation and start-up education will internalize the innovation and start-up into a self awareness and action of teachers and students so as to carry out the all-sided innovation education.

Reference[6] points out that major problems currently existing in the talent training of MEE include: obvious emphasis on "mechanics or electronics" in the talent training programs; imperfect innovation system, failing to fully implement the innovation education and concepts; more needed to strengthen the combination between theory and practice; the undergraduate graduation project mostly done in forms. With the above mentioned problems considered, this article raises thoughts for the training of innovative talents: prevent the mechanics and electronics from being separated from each other, some emphasis are available but the all-sided development is the major way; set Innovation and Practice course, intensify the guide to innovation theories; strengthen the teaching of basic courses, train basic skills for innovation; make the labs open and set up an innovative hardware platform; form systems and rules, establish innovation organizations and standardize innovation activities; promote the collegeenterprise cooperation and realize the training of innovative talents in practice. 
Reference [7] builds an innovation ability-centered practical teaching system consisting of five modules at three levels. The three levels are given as follows: first, a verification teaching at the basic level, aiming to reshow the theoretical contents via experiments; second, practical teaching at the improvement level, mostly the teaching in integrity and design, aiming obviously at the independent practical teaching, where independent practical projects are emphasized; third, practical teaching at the innovation level mostly the exploration teaching, aiming at the cooperation among graduation project, scientific research, a second class and open labs, etc. All levels of practical teaching shall highlight the emphasis for training in all stages, the verification practical teaching is to training students' basic capabilities in operation; the integrity practical teaching is to train students' capabilities in integrity; the design practical teaching is to train students' capabilities in innovative consciousness. Five modules: (1) Basic training of mechanical engineering, including mechanical drawing, mechanical parts, tolerance measurement and so on; (2) Basic training of mechanical process; (3) Training of advanced manufacturing technology and methods, including numerical control turning, numerical control milling, numerical control process centers, numerical control wire electrode cutting, numerical control electro-sparking process, light, mechanical and electrical integration system; (4) Training of electrical and electronic engineering, including SCM, PLC design and so on. (5) Innovative design and production, including topics or optional topics and research projects.

\section{E. A Talent Training Mode of Applied Mechanical and Electronic Engineering on the Basis of Competence}

Reference [8] builds an applied talent training mode integrating competence-based course system, practice system, examination and check system, comprehensive ability system and so on, of which the course training system consists of four modules as general fundamentals, electrical control technology, mechanical manufacturing technology and information management. The practice system consists of four modules as course experiment, practice in training base, practice in enterprises and special skill training. The comprehensive ability system consists of three abilities as basic abilities, cluster professional abilities, special job abilities; the examination and check system refers to an examination mode integrating module examination and check, examination and check at training base, industry examination and check.

Reference [9] Based on the analysis of the work scope, technical field and talent knowledge, abilities and quality structure of the employment groups as well as the German teaching mode borrowed, it, considering the college-running experience and conditions of their, adopts a segment teaching and module training mode, a course structure system gradually developing from the fundamentals to the profession "Fig. 3". The course structure system consists of four levels as basic teaching, professional teaching, specialty teaching, graduation project and professional practice; two stages as basic learning and subject learning. Within the three years of teaching, professional skills practice training module always goes through the whole course, forming a course structure system with four layers, two stages and one go-through.

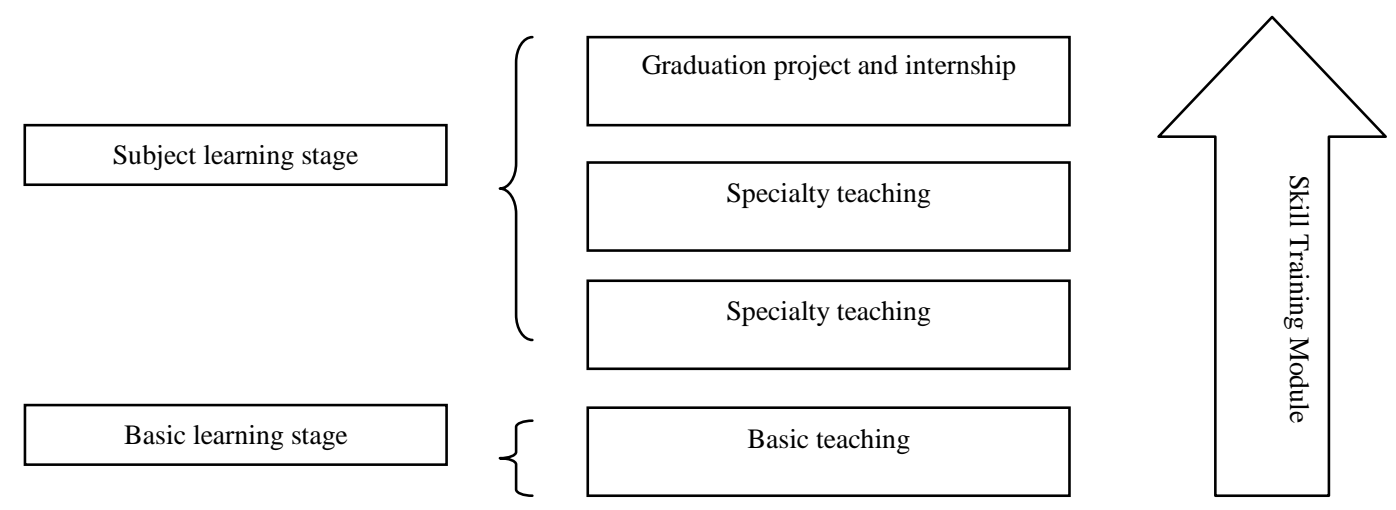

Fig. 3. Diagram of four layers, two stages and one go-through.

\section{F. Building of Software Application Training System in the MEE Talent Training Program}

Reference [10] points out that the MEE aims to train advanced applied talents in the mechanical and electrical industry. With the development of computer-aided design technologies, in order to achieve the goal, the training of software application skills related to subjects as mechanics, electronics, control and computer become more important than ever. Starting from the training of MEE-related comprehensive practical abilities, students are required to grasp at least one of the typical software such as program compilation, mechanical structure design and electronic circuit design and production. "Fig. 4" shows a training system of the MEE software. 


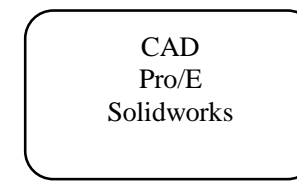

Mechanical structure design software

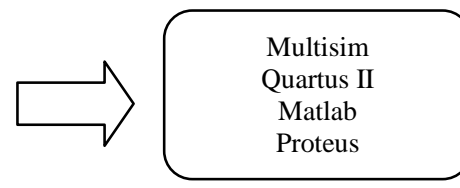

Circuit simulation software

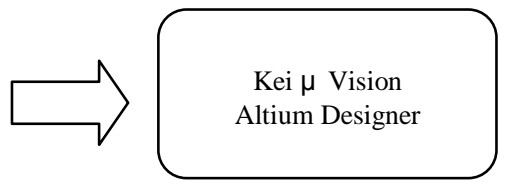

Electronic design and production software

Fig. 4. MEE Software Training System.

\section{G. Building of MEE Course Group}

Reference [11] analyzes the characteristics of MEE SCM Knowledge structure, after studying the internationally advanced CDIO engineering education model and the situations in the applied undergraduate colleges, this article proposes building a program of SCM course group and practice system, where the SCM course group is divided into SCM basic knowledge system, SCM core engineering knowledge system and SCM advanced engineering knowledge system, and the training of SCM practical abilities is divided into SCM basic practice abilities, SCM core engineering practice abilities as well as SCM advanced engineering practice abilities.

Reference [12] rebuilds the knowledge system relative to mechanical and electronic control course groups, aiming to make a top design for the training of the excellent engineers: Taking the actual mechanical and electronic system design application as background, the training of overall program design, analysis and innovation abilities of mechanical and electronic control system as goal, the definition of mechanical and electronic control system-how to describe it - how to analyze its performances as main line, according to students' cognitive rules, this article raises four knowledge structure modules namely basic theories of mechanical and electronic control system-description-performance analysis and assessment-comprehensive design, rebuilding a new system of the mechanical and electronic control system and integrating it to the "excellent engineers" talent training program.

\section{CONCLUSION}

The applied technology-based colleges are college-running type different from the research universities and higher vocational colleges. And they belong to undergraduate institutions meeting the needs of economic and social development, aiming at the training of applied and technical talents with unique college-running concepts, modes and rules, where the students trained in practical abilities are required stronger than those studying in the research universities, whose theoretical basis and professional skills are stronger than those studying in the vocational colleges [13]. Seen from the above training modes, the guiding ideologies of them are all to train and improve students' abilities in practice and innovation, enabling what the students learn to meet the needs of the society. And all the ways to achieve the training modes are to increase the practice accessing to the markets through which students will acquire more skills for employment.

\section{REFERENCES}

[1] Liu Jun, Li Rongbin, Wang Ye et al, Research on Applied Talent Training on the Basis of Engineering-Taking Mechanical and Electronic as an Example [J] Vocational \& Technical Education Forum, 2012,(7):52-54

[2] Gui Wei, Yao Cenglin, Zhang Hongxia, et al, Exploration and Practice of Applied Talent Training Modes under 3E Perspective-- Taking Mechanical and Electronic as an Example [J] Software Guide · Educational Technology, 2014,13(9):16-18

[3] Sun Aiwu, Practical Exploration of Underground Talent Training Modes of Mechanical and Electronic Engineering in High Vocational Education-Taking Nanjing Vocational Institution of Industry Technology as an Example, 2015,36(35):12-15.

[4] Shi Yanguo, Wang Xin, Yao Jiantao, et al, Research and Practice of Talent Training Modes on the Basis of CDIO Concept-Exploring the Training Modes of Mechanical and Electronic Engineering, Research in Teaching, 2015,(5):77-81

[5] Liu Jun, Liu Hongli, Huang Xiaoping, et al, Research and Practice of Innovative Start-up Education in Applied Universities-Taking Mechanical and Electronic Engineering as An Example [J] Value Engineering, 2016,35(25):222-223,224

[6] Jiang Feng, Exploration of Training of Innovative Talents Relative to Mechanical and Electronic Engineering [J] University Education, 2013,(2):68-69.

[7] Liu Xiaohong, Research on Developing Trends and Countermeasures for Practical Teaching of Mechanical and Electronic Engineering [J] Journal of Guangdong Polytechnic Normal University, 2011,32(6):5355. 2013,(2):68-69

[8] Guo Youdan, Building of Applied Talent Training Mode on the Basis of Competence [J]. Journal of Longyan University, 2014,32(5):71-77.

[9] Zhao Junsheng, Zhang Baocheng, Shi Yuanyuan, Reform and Innovation on Talent Training Modes of Mechanical and Electronic Engineering $[\mathrm{J}]$ Journal of Technology College Education $[\mathrm{J}]$ 2010,(1):53-55.

[10] Li Xu, Kang Jiang, Liu Lifang, Training of Software Application Skills of Mechanical and Electronic Engineering [J] 2016,38(3):8-11..

[11] Chen Weigui, Research and Practice of SCM Course Group Setting in Mechanical and Electronic Engineering [J] Theory and Practice of Contemporary Education, 2011,3(5):63-65.

[12] Wang Heng, Hua Guoran, Zhu Longbiao, et al, Research on Building of Mechanical and Electronic Control Course Group for Training of Excellent Engineers [J] The Science Education Article Collects, 2016,0(1):50-51.

[13] Chen Yongzhu, Yang Yong, Discussion on Talent Training Modes of Mechanical and Electronic Engineering at Applied UniversitiesTaking Mechanical and Electronic Engineering at Guangdong Polytechnic Normal University $[\mathrm{J}]$ University Education, 2015,0(6):135-137. 